\title{
Extraforaminal Lumbar Interbody Fusion for Cage Migration after Screw Removal: A Case Report
}

\author{
Myung Hoon $\mathrm{Kim}^{1}$, Seok Won $\mathrm{Kim}^{1}$, Sung Hoon $\mathrm{Kim}^{2}$, Hyeun Sung $\mathrm{Kim}^{3}$ \\ Department of Neurosurgery ${ }^{l}$, College of Medicine, Chosun University, Gwangju, \\ Department of Rehabilitation Medicine 2 , Wonju Christian Hospital, Yonsei University Wonju College of Medicine, Wonju, Korea \\ Department of Neurosurgery, Heori Sarang Hospital, Daejeon, Republic of Korea
}

The use of titanium cages for posterior lumbar interbody fusion (PLIF) has gained popularity because it offers the advantages of anterior column support and stabilization. However, cage migration into the spinal canal may have severe or disastrous consequences. Here, the authors report an unexpected case of posterior migration of fusion cages after screw removal in a patient that underwent PLIF 12 months previously. Removal of the offending cages through revision extraforaminal lumbar interbody fusion (ELIF) with percutaneous screw fixation successfully managed this complication. As far as the authors' knowledge, this is the first case report to describe this sort of complication, and cautions that care must be taken to prevent cage migration.

Key Words: Cage $\cdot$ Complication

\section{INTRODUCTION}

Although posterior lumbar interbody fusion (PLIF) is a widely accepted procedure, perioperative and postoperative complications are still encountered. Of these complications, postoperative cage migration could result in narrowing of the disc space and foraminal region, and even directly compress the dural sac and nerve root, which are one of the most severe postoperative complications. In such cases, removal of the migrated cage is necessary, but revision surgery for cage migration using the same route is technically demanding ${ }^{5,11)}$. In particular, dural retraction and nerve root mobilization are difficult due to massive epidural fibrosis. The main risk factors for cage migration after PLIF are known to be total facetectomy and a lack of screw fixation ${ }^{210)}$. Although several reports of posterior cage migration after PLIF have been published,

- Received: January 15, 2013 - Revised: May 23, 2013

- Accepted: June 25, 2013

Corresponding Author: Seok Won Kim, MD, PhD

Department of Neurosurgery, School of Medicine, Chosun University,

588, Seosuk-dong, Dong-gu, Gwangju-city, 501-717, Republic of Korea

Tel: +82-62-220-3126, Fax: + 82-62-227-4575

E-mail: ns64902@hanmail.net/chosunns@chosun.ac.kr

This study was supported by research funds from chosun university hospital 2012 no report has been issued on cage migration after screw removal. Here, we report a unique case of this complication and include a review of the relevant literature.

\section{CASE REPORT}

A 55-year-old man initially presented with disabling pain in both legs with claudication of 5 months duration. Radiological studies, including simple radiographs and magnetic resonance imaging (MRI) studies, revealed right foraminal stenosis at the L4-L5 level. Preoperative laboratory tests and bone marrow densitometry (BMD) results were all within normal ranges. He underwent L4-L5 PLIF using Stryker titaniumthreaded cages (length $25 \mathrm{~mm}$, height $9 \mathrm{~mm}$ ) with autogenous local bone chips following posterior instrumentation. Radiographs obtained immediately after surgery showed appropriate positioning of the cages, and his presenting symptoms were much improved. At his 12-month follow-up, the leg pain and claudication symptoms had resolved, but he complained of back pain, late-onset back discomfort, and a reduced range of motion (ROM). He requested implant removal. Plain radiographs showed that cage positions had been well-maintained (Fig. 1). Because he was believed to have solid arthrodesis and no other pain generator, such as, adjacent segment degeneration, flat back deformity, or pseudoarthrosis, we considered that spine implant removal would relieve the back pain 


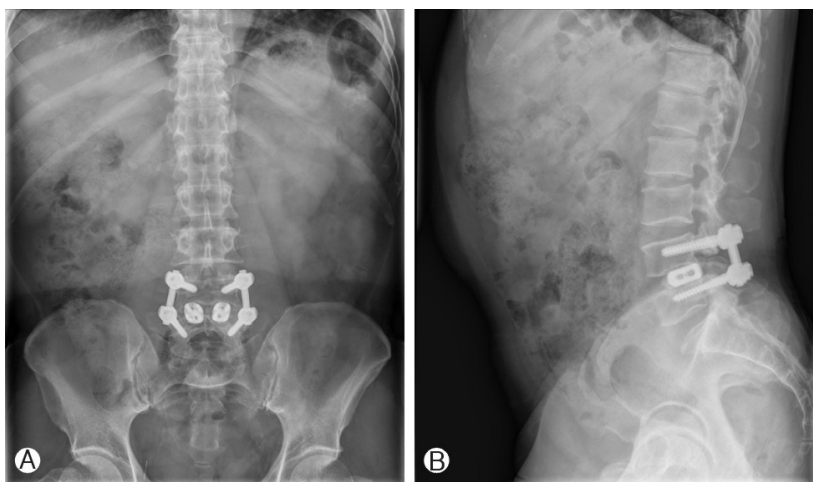

Fig. 1. A \& B: Postoperative simple radiographs obtained 12 months after PLIF show appropriate positioning of fusion cages.

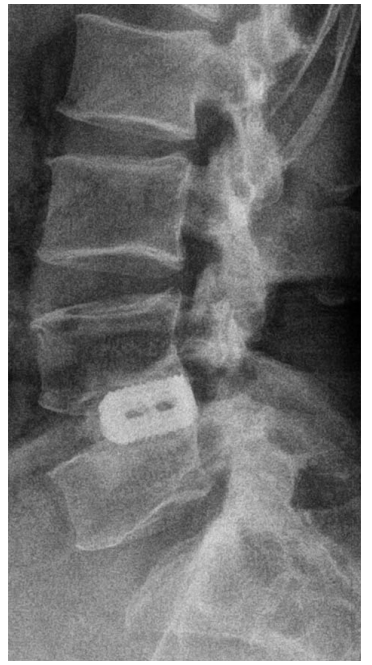

Fig. 2. Simple lateral radiograph after screw removal shows appropriate and well-maintained cages.

and discomfort, which were responsive to injections of lidocaine. Pedicular screws were removed at 12 months after PLIF (Fig. 2). However, one month after screw removal, the pain in both legs severely worsened in spite of aggressive analgesic administration. Plain radiographs and MRI showed that posterior migration of the inserted into the disc space (Fig. 3). Patient was scheduled for extraforaminal lumbar inter-body fusion (ELIF) with percutaneous screw fixation, which enables facile exposure of the exiting nerve root for cage removal without violating previous posterior musculoligamentous structures or bony stabilizers of the spine. During revision surgery, after removing both offending cages, two peek cages (length $25 \mathrm{~mm}$, height $9 \mathrm{~mm}$ ) were inserted into the disc space, and percutaneous screw fixation with compression was applied to the disc space to prevent further cage migration. Dramatic improvements of severe back and radiating pain were achieved immediately after revision surgery (Fig. 4). At his 6-month follow-up, he was symptom free and plain radiographs and MR images showed that cage positions had not changed.
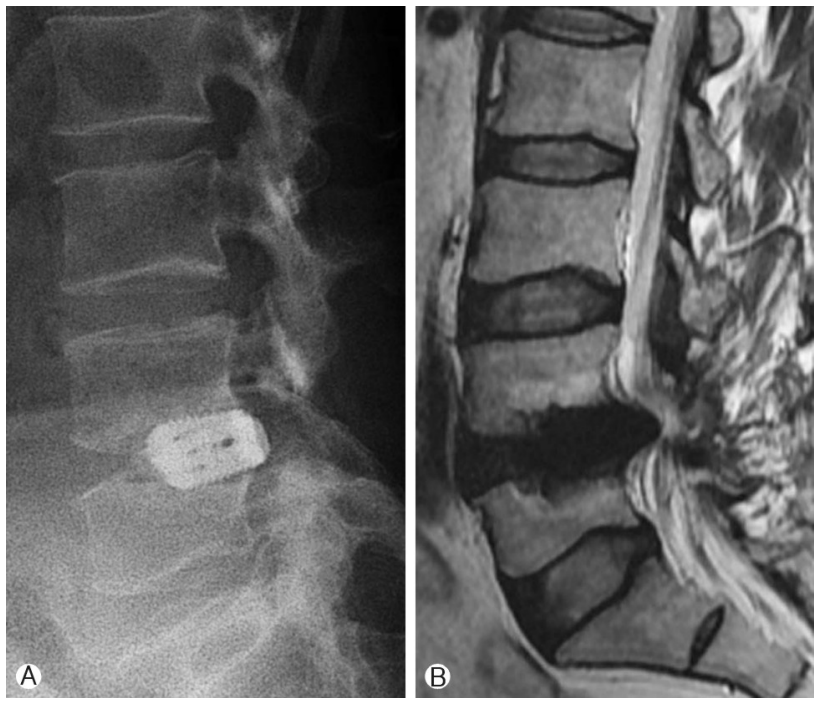

Fig. 3. A \& B: Simple lateral radiograph and T2 sagittal magnetic resonance image (MRI) taken one month after screw removal reveal posterior cage migration.
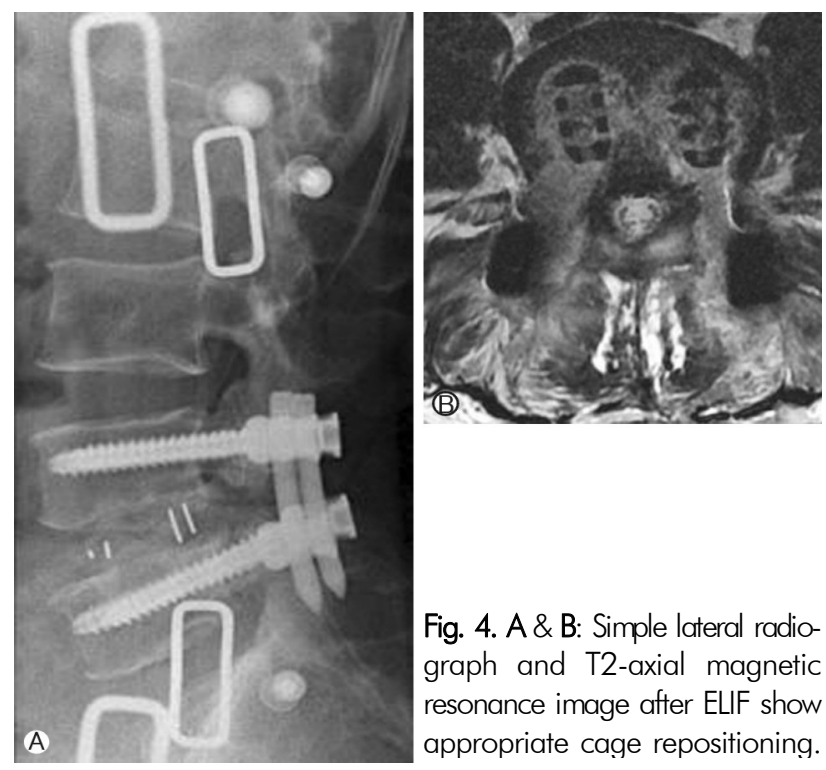

Fig. 4. A\& B: Simple lateral radiograph and T2-axial magnetic resonance image after ELIF show appropriate cage repositioning.

\section{DISCUSSION}

The use of titanium cages in PLIF has gained popularity in the context of spinal fusion, because of its advantages in terms of the support and stabilization of the anterior col$u_{m n}{ }^{6,9)}$. Although current PLIF procedures are the result of considerable developments, some cage-related complications, such as, cage migration or subsidence, sometimes occur. However, few cage-related complications have been reported. Brodke et al. ${ }^{1)}$ and Lund et al. ${ }^{8)}$ biomechanically tested the initial stability of PLIF alone and with additional screw fixation, and 
both studies supported the role of additional screw fixation in terms of preventing cage retropulsion, markedly increasing stiffness in axial compression, and more importantly, in terms of increasing flexion-extension torque ${ }^{1,8)}$. Although previous reports have described posterior migration of static cages as a potential complication, to the best of our knowledge, this case is the first reported case cage migration after implant removal causing new radiculopathy. The merits of spine implant removal for pain relief in patients with fusion remain a matter of debate ${ }^{3,477}$. Kim et al. ${ }^{7}$ reported that a retained implant can be a pain generator in patients with back pain and discomfort after spine surgery, and suggested that implant removal might provide significant pain relief. There are some theories as to why remained implants can be a source of back pain. Inflammation caused by infectious or non-infectious causes such as metallic erosion, debris, and local irritation by prominent implants have been proposed to cause implantrelated pain ${ }^{7}$. In our patient, we believe solid fusion was achieved because of adequate positioning of the cages during 12 months of follow-up after PLIF. We should have confirmed solid fusion through computed tomography (CT) scan before implant removal. Although spinal implant removal is conducted for patients with late-onset discomfort and back pain after spinal instrumentation, implant removal must be approached with caution. In particular, loss of compressive force applied to segment due to screw removal can result in cage migration. In our patient, we unexpectedly experienced posterior cage migration 1 month after screw removal. We suggest that ELIF with percutaneous screw fixation would successfully manage this complication without violating previous musculoligamentous structures or bony stabilizers of the spine.

\section{CONCLUSION}

We report a case of unexpected cage migration after implant removal at 12 months after PLIF. This case cautions that care must be taken and adequate radiological studies including CT scan should be performed before spinal implant removal.

\section{REFERENCES}

1. Brodke DS, Dick JC, Kunz DN, McCave R, Zdeblick TA: Posterior lumbar interbody fusion: A biomechanical comparison, including a new threaded cage. Spine 22:21-31, 1997

2. Chen L, Yang H, Tang T: Cage migration in spondylolisthesis treated with posterior lumbar interbody fusion BAK cages. Spine 30:2171-2175, 2005

3. Deckey JE, Coert C, Bradford DS: Loss of sagittal plane correction after removal of spinal implants. Spine 25:2453-2460, 2000

4. Hume M, Capen DA, Nelson RW, Nagelberg S, Thomas JC Jr: Outcome after Wiltse pedicle screw removal. J spinal Disord 9:121-124, 1996

5. Kimura H, Shikata J, Odate S, Soeda T, Yamamura S: Risk Factors for Cage Retropulsion After Posterior Lumbar Interbody Fusion. Spine 37:1164-1169, 2012

6. Kim HJ, Cho KH, Shin YS, Yoon SH, Cho KG: Minimally Invasive Posterior Lumbar Interbody Fusion With Threaded Fusion Cage (TFC). J Korean Neurosurg Soc 30:247-253, 2001

7. Kim SW, Ju CI, Kim CG, Lee SM, Shin H: Efficacy of Spinal Implant Removal after Thoracolumbar Junction Fusion. J Korean Neurosurg Soc 43:139-142, 2008

8. Lund T, Oxland TR, Jost B, Cripton P, Grassmann S, Etter C, et al.: Interbody cage stabilization in the lumbar spine: Biomechanical evaluation of cage design, posterior instrumentation, and bone density. J Bone Joint Surg Br 80:351-359, 1998

9. Park KW, Kim DY, Lee SG, Yoo CJ, Kim WK, Park CW: Longterm Results of single Level Posterior Lumbar Interbody Fusion with stand-alone Cage in Degenerative. Korean J Spine 4(3): 123-128, 2007

10. Uzi EA, Dabby D, Tolessa E, Finkelstein JA: Early retropulsion of titanium-threaded cages after posterior lumbar interbody fusion: a report of two cases. Spine 26:1073-1075, 2001

11. Wetzel FT, LaRocca H: The failed posterior lumbar interbody fusion. Spine 16:839-845, 1991 